\title{
ANTONIO GAMONEDA: DIVERGENCIA DE LA ACTUALIDAD; DESINSTALACIÓN EN EL PRESENTE
}

\author{
Fernando R. DE LA FLOR
}

Universidad de Salamanca

\section{$\mathbf{E}$} xtrañeza de mundo ${ }^{1}$

En este volumen -y también en aquella precisa ocasión y evento que ahora aquí recoge ${ }^{2}-$ se cumple una suerte de ritual inherente a la constitución del campo literario de nustros días. Pues, en efecto, aquí se logra reunir -y no es la única vez que esto sucede en los últimos tiempos-a un autor con la parte de la crítica y de la Academia que se ha visto más profundamente afectada e interpelada por la llamada estético-ideológica de su obra. Hasta el punto de haberla acompañado en su travesía desde el silencio y la desatención pasada hasta su actual abierta aceptación. Ya que por un momento me voy a ocupar aquí de cuestiones que tienen que ver al cabo con la recepción, puedo con sinceridad decir que muchos de nosotros nos encontrábamos mas cómodos en la primera fase de lucha por el reconocimiento del campo, cuando abogábamos en defensa de una «literatura menor» en el sentido deleuziano ${ }^{3}$, que lo estamos en este segundo momento donde nos encontramos ante una literatura que se puede dar por establecida, inscrita definitivamente en el campo y por lo tanto en la historia. La marginalidad es algo que uno conquista por sí mismo, en razón incluso de sus propios méritos solipsistas a la hora de oponerse al espíritu de los tiempos, pero el éxito siempre se debe a unas condiciones exteriores, relativas a la propia economía del campo socioliterario; condiciones por las que en todo caso conviene siempre preguntarse, inaugurando respecto a ello un pensamiento de la sospecha.

Empiezo por declarar que, en lo que a mí se refiere, lo que creo de más sustantivo que podría aquí aportar referido al poeta quedó ya expresado y suficientemente dicho en el prólogo que en su día hicimos Amelia Gamoneda y yo a la edición de la antología Sílabas negras ${ }^{4}$.

\footnotetext{
${ }^{1}$ La entradilla dirige la atención hacia la obra del filósofo P. Sloterdijk (2001), Extrañamiento de mundo, casi homónima, y que es un análisis fenomenológico del espíritu falto o apartado del mundo.

2 Se trata de la celebración en la Universidad Autónoma de Madrid del congreso «Poesía y divergencia VII. Antonio Gamoneda (la palabra dañada)», entre los días 15 y 17 de abril de 2009.

${ }^{3}$ «Literatura menor» que queda definida en el ensayo de G. Deleuze y F. Guattari (1975), Kafka. Por una literatura menor.

${ }^{4}$ Gamoneda; R. de la Flor (2006), Sílabas negras.
} 
No he variado de opinión sobre el hecho a mi parecer determinante de una historización precisa de la escritura de nuestro autor, la calidad que ostenta en cuanto en ella se realiza una suerte de síntesis simbólica epocal, y me sigue, en consecuencia, pareciendo como insoslayable abordar el hecho de la interdependencia plena que en aquella se manifiesta con relación a un tiempo y a una verdaderamente peculiar historia española, con la que creo que está íntimamente relacionada.

Frente a quienes han optado por explorar de manera prácticamente autónoma el arte verbal de Antonio Gamoneda, refiriéndole constantemente a los misterios «eleusinos» de la producción de un lenguaje poético y al ámbito cerrado de la escritura y de la intertextualidad -como si nuestro autor fuera ante todo y antes que nada un enfermo de literatosis-, soy indudablemente de quienes, por el contrario, quisieran remitirlo a una matriz explicativa y hermenéutica que solo se deja leer a través de una precisa referencialidad histórico-política. Creo que tal escritura de tan singular autor ha ofrecido la síntesis simbólica maestra de un momento o momentos precisos en que han estado envueltos unos tiempos españoles, estableciendo la «anatomía simbólica» de lo que bien podríamos denominar como una suerte de «noche española ${ }^{5}$ (para aludir con esta sugerente expresión a una atmósfera determinada por el subdesarrollo psicosocial, que ha sido, no lo olvidemos, una característica de lo peninsular hasta hace prácticamente dos días ${ }^{6}$ ).

La obra prolongaría así indefinidamente, haciéndola penetrar con decisión en nuestro tiempo, una sombra trágica y ominosa que planea en la forma de duelo permanente por un pasado irresuelto, y para decirlo esta vez con Walter Benjamin -quien mucho se ocupó de estas cuestiones de la culpa histórica-, de un pasado irredimible, que no conoce la fácil redención absolutoria para su pecado ${ }^{7}$. Son las deudas del ayer, la historia como catástrofe colectiva y personal que se proyecta espectralmente con sus «lápidas» abiertas en interrogante, no permitiendo -al haber colapsado el pensamiento mesiánico-cristiano que le daría salida- apertura alguna hacia la redención o el posible olvido. Ello, podemos suponer, amenaza la constitución misma de estos tiempos y entra en íntimo desacuerdo con ellos. Un tiempo, el nuestro, que bien podemos caracterizar por la extensión de una general autocomplacencia de haber llegado a donde creemos haber llegado: por fin al «interior» del mundo del capital, convertidos en una democracia liberal esencialmente determinada por el individualismo egohedonista. Y es que, como ha podido observar el filósofo contemporáneo: «Daremos por hecho que el reino de la necesidad y del dolor ha dejado sitio al reino de la libertad y el placer de vivir» ${ }^{8}$.

Aquel «subdesarrollo», la vieja inmadurez consustancial al espacio psico-histórico hispano, con su peso decisivo en el imaginario, y su papel de núcleo de insatisfacción permanente es, creo, la clavija

\footnotetext{
${ }^{5}$ Es esta una construcción conceptual que se ha difundido para aludir a cierto arte español, y que ha puesto en circulación A. González (2000), El Resto. Una historia invisible del arte contemporáneo.

${ }^{6}$ V. Navarro (2006), El subdesarrollo social en España.

7 J. J. Lanz (2009), «La memoria y su silencio: Descripción de la mentira (1977) de Antonio Gamoneda y la memoria callada del franquismo y de la Transición», Anales, 101-116.

${ }^{8}$ P. Sloterdijk (2008), En el interior del mundo del capital, 253. La observación pone en evidencia el victimismo tradicional de las élites intelectuales en Occidente. Otros sociofilósofos avanzan también en estos momentos en lo que parece ser la inmersión occidental en una suerte de «felicidad paradójica» (G. Lipovetsky, 2007, La felicidad paradójica. Ensayo sobre la sociedad del hiperconsumo) condicionada por el acceso a un lujo y una seguridad finalmente democratizada (G. Lipovetsky, 2004, El lujo eterno: de la era de lo sagrado al tiempo de las marcas).
} 
que ha movido hasta ahora la mejor producción discursiva nacional, y es, en todo caso, lo que ha caracterizado $-\mathrm{y}$ puede que todavía caracterice, en su, digamos, estructura profunda- la peculiar situación de mundo que entre nosotros tradicionalmente se ha dado.

Extraña situación de mundo, la española (si puede llamarse todavía así), en donde hace inmersión Gamoneda y fuera de la cual no se explicaría tal obra. Extraña, en principio porque, por decirlo de una manera gráfica, en ella se ha atravesado, como en un suspiro (sobre todo si lo contemplamos con los ojos del poeta que, en efecto, los llegó a perforar con su cuerpo biopolítico y discursivo), al menos cuatro marcos epocales de muy distinto signo: La Guerra Civil ${ }^{9}$; la dicta blanda persuasiva e íntimamente corruptora del franquismo; también el momento singular del espejismo transicional en que la Revolución evolucionó hacia simple Cambio, y, finalmente, ha logrado llegar -y esto es lo notable que destacaremos aquí- a la opulencia posmoderna, donde ha cuajado el estado cultural (hay que afirmar que estado cultural «a la española», de nuevo, no desde luego y por decirlo así, a la francesa, a lo Fumaroli ${ }^{10}$ ), y donde se desvanece en el aire el fantasma amenazador de una (re)caída en la fatal demodernización. Último estadio este en que vivimos perfectamente instalados, y donde yo, por cierto, me sitúo con la intención precisa de por esta vez leer solo desde allí a don Gamoneda. De modo que, en efecto, estamos ante la obra de un productor simbólico que ha tenido suerte, pues durante su vida ha visto cambiar la condición humana y puede dar testimonio de ello. Es ese valor residualtestimonial lo que la obra pone en juego y lo que de ella resulta aún valioso.

No deseo salir de los grandes rasgos apuntados en esta consideración de lo histórico para entrar aquí y ahora en la gramatología, ni en cualquier otra forma de análisis que resultara puramente textual, en el breve espacio que me ha sido concedido en este volumen. En otros lugares críticos he explanado la vinculación y la dependencia que el discurso gamonediano manifestaba con respecto al duelo y luto por la guerra ${ }^{11}$; también a lo que siguió a esta, que yo interpreto por parte de Gamoneda como abrazamiento discursivo de la condición de carencia material, de súbita restricción y astringencia en el desarrollo de las libidos fundantes, reprimidas o autoreprimidas (después de todo eso viene a significar en el plano psicoanalítico el papel del franquismo), para al cabo hacer de ello una gran virtud, al estilo de lo que ya una vez conocimos históricamente como «santa pobreza». Restricción que adornó como una corona, aunque ciertamente hecha de espinas, el way of life hispano caurentañista, marcado por la señal contundente del neoestoicismo. Pobreza que, como tal, incluso fue exaltada en ocasión memorable del discurso de recepción al Premio Cervantes por nuestro autor ${ }^{12}$. Bien, se reconocerá que,

\footnotetext{
${ }^{9}$ Guerra Civil de la que Gamoneda ha ofrecido una síntesis simbólica fuera de la línea habitual del «Otra vez el ayer» (como titula a su libro sobre la cuestión A. Trapiello, 1996, Otra vez el ayer. Los intelectuales ante al Guerra Civil, Madrid, Casa del Libro).

${ }^{10} \mathrm{Me}$ refiero, naturalmente, a la situación de la cultura occidental de última hora y a su cooptación por la política que ha podido trazar M. Fumaroli (2007), El «estado cultura»l: de la oligarquía demagógica a la conversión de la cultura en mercancía publicitaria.

${ }^{11}$ Duelo, en definitiva, por la historia, por lo histórico mismo como relato del camino de desventura emprendido por la humanidad en su largo transcurso por el tiempo, de lo que ha dado cuenta el libro de un inteligente analista de estas cuestiones, E. Ocaña (2000), El duelo por la historia, y que también ha desarrollado, más recientemente, R. Mate (2006), Medianoche en la historia. Comentarios a las tesis de Walter Benjamín «sobre el concepto de historia».

12 A. Gamoneda (2007), «Palabras pronunciadas por Antonio Gamoneda al recoger el Premio Cervantes de Literatura en Alcalá de Henares», República de las Letras.
} 
de pronto, elevar aquella carencia a fuerza destinadora del discurso y leitmotiv bioliterario suponía hacer un homenaje después de todo ambiguo a la autarquía, a los «años de plomo», cuyo fondo íntimamente aniquilador y precipitante de melancolía contenía también un paradójico posicionamiento moral que fuera en su día elevado a característica ontológica central en la constitución del hombre de sentimiento y de acción por la ascética castellana y por la llamada entre los nuestros «literatura del pobre»; estamos situados ante la desilusión mundana, las escrituras del desengaño ${ }^{13}$. Lo precario del mundo, en efecto, se revelaba mejor en los tiempos en que el paradigma desviado hispano se convertía en un espacio estanco dentro del general desarrollo del capitalismo occidental

Hemos visto pues a Gamoneda acudir en legitimación de aquella carencia, después de que tanto Benjamín ${ }^{14}$, como, algo después, el propio Heidegger ${ }^{15}$, rescataran y reformularan esta idea de menesterosidad ontológica, otra vez en tiempos que fueron de penuria para Occidente. Y, en fin, fuera de haber señalado ya esto, también creo haber argumentado con alguna coherencia que la Transición fue el motor discursivo para este hombre, que en ese preciso espacio dio en inaugurar verdaderamente su carrera, su cursus entre nosotros, trayendo la mala nueva de la permanencia e invariante de un estado de necesidad, de carencia, del ser, de un malestar existencial y de una fundamental incapacidad de conectar el yo solipsista con el resto del cuerpo social en el horizonte de una final vivencia del «estarjuntos».

Allí, en aquel momento hiperpolítico transicional quedaron en sustancia formuladas las condiciones de lo que sería en adelante su «producción de presencia» ${ }^{16} \mathrm{y}$, para decirlo ya con el término que con mucho acierto el poeta o los comitentes de aquel encuentro eligieron como título o exergo Poesía y divergencia-, ahí empezó también la historia de la construcción discursiva y vital del poeta en términos que esencial, profundamente, podemos entender como de «divergencia». Lo cual no es, por cierto, cosa de nada. Se trata de un concepto sobre el que una vez que ha sido puesto en juego nos veremos en adelante obligados a reflexionar sobre su sentido, dado que no podemos suponer que su presencia aquí sea gratuita en el exergo, lema y hasta motivo mismo de esta ocasión que reúne al poeta y a su crítica. Sino que, precisamente estamos comprometidos a entenderlo, y yo diría que, de nuevo, en una dimensión histórica, política, más que en una estrictamente referida a maniobras de simple distinción diferenciadora en el campo de las letras ${ }^{17}$, como solo en un primer momento podría parecer.

Y pese a ello, este término de «divergencia» yo estoy seguro que la mayoría de los analistas reunidos tendrían la tentación de interpretarlo, de nuevo, en un sentido prioritariamente a-histórico, o,

\footnotetext{
${ }^{13}$ La conexión de la obra del poeta con este referente conceptual del pensamiento tradicional hispano no ha sido ciertamente establecida por la crítica, sino acaso sólo en la forma de vagas alusiones al «barroco» (siempre más como procedimiento y orden de lo lingüístico, que como ideología de lo nacional profundo). Para la vertiente estrictamente histórica de este «desengaño», que puede leerse también como melancolía, véase mi libro R. de la Flor (2007), La era melancólica. Figuras del imaginario barroco.

${ }^{14}$ Véase W. Benjamin (1989), «Experiencia y pobreza», en Discursos interrumpidos I, 165-175.

${ }^{15}$ M. Heidegger (2006), La pobreza.

16 «Producción de presencia», la fórmula que hace referencia a la construcción de una posición en este caso en el campo de las letras pertenece a H. Gumbrecht (2005), Producción de presencia. Lo que el significado no puede transmitir.

${ }^{17}$ La mecánica de la distinción, con todo, preside la inscripción en un campo y es su condición ineludible. Véase a este propósito el tratado de P. Bordieu (1988), La distinción. Criterios y bases sociales del gusto.
} 
en todo caso, estrictamente restringido al campo literario. Es decir como referido exclusivamente a la propia configuración de posición diferenciadora respecto al canon de letras españolas contemporáneas, del cual, efectivamente, la obra y la posición intelectual de Gamoneda se muestran como abiertamente «en divergencia». Aunque esto último es, por cierto, menos grave que aquello primero. Disonar de un medio profesional no es o mismo que entrar en grave desacuerdo con el signo comunitario de los tiempos

Hay que decir que el propio poeta se ha esforzado en operar con los signos de esta divergencia, y lo hace en primer y fundamental lugar diferendo con respecto al nicho generacional que la crítica le tenía preparado, y que, enseguida, también se muestra como toma de posición antinómica frente a la línea poética que se consagra como la canónica en el espíritu de la actualidad ${ }^{18}$. Pero la cuestión puede adoptar también otros rasgos más impensados -y esta vez de matiz biografemático-, cuando, por ejemplo, Antonio Gamoneda, y es un caso muy excepcional, se repliega haciéndose fuerte en esa vieja circunscripción a la que llamamos todavía «provincia», y con espíritu mesetario hace de ella fundamento vital en unos tiempos donde, precisamente, la dictadura de las metrópolis culturales y la presión fascinadora que estos ejercen sobre las elites intelectuales ha llegado a su punto máximo de atracción polar ${ }^{19}$. Muestra así, creemos, el valor de lo periférico, ensanchando una noción restricta acerca de lo que es el campo de letras y quien lo ocupa.

\section{(In) convergence Culture ${ }^{20}$}

Sin negar estos filos del concepto «divergencia», me gustaría extender el mismo ahora a otro ámbito. Este, también, por lo que se puede ver, un tanto desertado por la crítica, en ocasiones diríamos que poco predispuesta a analizar en qué tipo de situación de mundo vivimos, y, en consecuencia, poco interesada en inscribir a los productores de discurso frente a lo que resulta ser ese mismo tiempo-ahora. Este lugar nuevo con respecto al cual el poeta y la obra podrían resultar «divergentes» no es otro que el propio campo de la recepción hoy constituido, el punto preciso en que un texto se sitúa en la dimensión del presente absoluto de sus lecturas de acogida, el punto quimérico donde una lectura de mundo impacta en el imaginario colectivo, legitimándolo y reforzándole, o, como aquí nos tememos que sucede en el particular caso de tal escritura, negándolo y separándose de él, estableciendo una polaridad en tensión conflictiva.

Por cierto que este del presente es el único tiempo que la postmodernidad considera y valora, una vez que hemos entendido que toda evocación de la memoria y el pasado no es sino una coartada

\footnotetext{
${ }^{18}$ Siempre discreto, Antonio Gamoneda, antes de realizar gestos elocuentes de disconformidad y ataque, ha preferido que sean sus múltiples enemigos quienes se ocupen de sacarle del campo de actualidad y recluirle en estrechos límites temporales que facilitan su desactivación, en la forma de una personalidad de otros días y de otros tiempos.

${ }^{19}$ De ello, que yo sepa, solo ha dado cuenta en su día F. Martínez García (1991), Gamoneda, una poética temporalizada en el espacio leonés. He revisado la cuestión de la «provincia» para el caso de Claudio Rodríguez, un poeta próximo al espíritu de Antonio Gamoneda, en R. de la Flor (2008), «Glocal. Claudio Rodríguez y al poética de la provincia», Aventura. Revista anual del Seminario Claudio Rodríguez, 48-73.

${ }^{20}$ Contrafacto aquí el título de una de las «biblias» del posmodernismo mediático, la de H. Jenkins (2009), Convergente Culture. La cultura de la convergencia de los medios de comunicación.
} 
discursiva para oscurecer las condiciones mismas en que el presente, en efecto, se nos presenta ${ }^{21}$. La dictadura del presente y la lógica de la novedad son dos leyes del marco de acción donde se encuadran las prácticas de la modernidad, y habremos de reconocer por lo que valga que a ello se deben adaptar todas las representaciones simbólicas. Las elaboradas por el propio Antonio Gamoneda no podrían quedar exentas, aun cuando lo que sí puede suceder, como sí creo que sucede, es que situadas en un extremo antagónico de lo que conforma el habitus del intelectual, y logra animar frente a ello una posición dialéctica decididamente no sumisa, y, por consiguiente, determinada por algún tipo de aura resistente o, acaso, mejor, «divergente», ofreciendo salidas insospechadas al nudo conflictivo de la vivencia de actualidad.

Digo que hasta ahora, por lo que he visto, la crítica ha leído en positivo -y según condicionamientos de nuevo interiores a la propia construcción y esfera autónoma de una historia de la literatura española contemporánea- el encuentro entre el texto de Gamoneda y sus sucesivos presentes. En efecto, la acogida que desde 1987 viene teniendo la obra de Antonio Gamoneda ha sido celebrada tradicionalmente como un acto de reparación histórica, algo que de suyo el sistema debía al poeta, en razón fundamentalmente de los largos años que había mantenido a éste en situación de stand by.

Frente a esta suerte de pax poética y final feliz, es hora pues, por un momento, de hacer recuperar al concepto de divergencia todo el brillo dialéctico que en él se manifiesta, y hacerlo funcionar en unos escenarios considerablemente más vastos que aquellos que se juegan dentro del llamado «mundillo de las letras», donde efectivamente, tiene sentido hablar de reinscripciones de lo olvidado, pasaje al canon después de varias estaciones penitenciales y conquista de autoridad ejemplar sobre la grey, que en el pasado se habría mostrado como renuente y desafecta a tal mensaje. Pero todo ello, se comprenderá, no afecta decisivamente a la esfera de la recepción que aquí evocamos y al imaginario epocal que la sustenta y la determina, en cuanto estos son escenarios mayores y definitivamente marcados pro el signo de lo histórico

Volvamos, pues, entonces al valor y sentido fuerte que puede alcanzar esa divergencia, dado que la clamorosa recepción de Gamoneda en los últimos tiempos, su instalación definitiva en el panteón de las letras hispanas, sugiere en cierto modo que se habría desactivado el valor que a la palabra «divergencia» misma se le pueda conceder, atribuida en relación a su obra o a su propia vida, y ello en cuanto, se reconocerá, que el concepto propiamente viene a significar y a ser sinónimo de una desinstalación en un mundo falso, de un extrañamiento y autoexilio de la doxa u opinión común establecida. En fin, de una incomodidad manifiesta en o con el presente, que a su vez no reconoce, y antes bien, sistemáticamente segrega y condena a todo aquello que no coincida exactamente con su axiología, con su mapa de valores establecidos y proclamados en la esfera estética donde ejerce su dominio. La emergencia sorpresiva de tal concepto en el mismo frontis de esta convocatoria nos obliga

${ }^{21}$ La memoria, efectivamente, comienza a tener sus desafectos. No demos por evidente su reinado entre nosotros. Véase el análisis que de la cuestión hace uno de sus más calificados pensadores de actualidad, T. Todorov (2000), Los abusos de la memoria. 
a pensar que el poeta, pese a todo, se sigue manteniendo en posición de divergencia. Pero nos debemos preguntar seriamente, ¿de divergencia respecto a qué?

En efecto, entonces, frente a quienes exaltan la convergencia de la escritura de Gamoneda con nuestro tiempo, dándola como natural después de una larga travesía de silencios, yo preferiría, al menos en este foro (que aparentemente da cuenta y exalta también una suerte de colusión final de celebración de reconocimiento de un poeta por la comunidad de intérpretes de su mismo tiempo), señalar en ello, justamente, todo lo que, todavía, de divergente se muestra poderosamente en esta escritura; todo lo que en ella hay y se deja leer allí como poseído de un efecto de disidencia renuente a la aceptación de lo dado, también de extrañamiento, de lejanía ${ }^{22}$, insinuando poderosamente su distancia también respecto a cualquier valor de situación presente. Y obligándonos en consecuencia a pensar, más que en instrumentar nuevos discursos de la afinidad, si acaso hay también algo entre nosotros -los analistas de hoy- y el poeta que nos separa efectivamente de él, que lo lleva en definitiva a dissedere, a colocarse en otro espacio diferente a éste para el que parece haber sido destinado. Es quizá aquello que Tomás Sánchez Santiago ha definido para el poeta como permanente situación de «fuera de tono», fuera de tono epocal, final incomodidad del poeta con su tiempo, y, naturalmente, también de este con él ${ }^{23}$. Ello hasta hacer un punto inexplicable el hecho mismo de una recepción dentro de la configuración de la actualidad (de los mundos de la vida practicables y practicados), al menos de una recepción sincera.

La lógica misma que posee a todo lo divergente, pensamos que, en realidad, debía haber terminado por hacerlo resultar, a tal poeta, como prácticamente inaudible en el ágora mediática posmoderna, dado el concierto de las voces que podrían reclutarse en contra. Es esta una realidad que se puede desprender del análisis axiomático de la sociedad del espectáculo, que ha realizado un Guy Debord $^{24}$, y que ha confirmado recientemente Borys Groys en su obra Bajo sospecha ${ }^{25}$, y también en la exploración que el filósofo de la cultura ha llevado a cabo sobre aquello que conforma en verdad la lógica superior a que se somete cualquier situación cultural en el capitalismo tardío ${ }^{26}$. Es lo convergente (de nuevo, Jenkins ${ }^{27}$ ) lo que anima el fondo de la cultura posmoderna.

Quiero decir con ello, y desde este punto de vista de los paradigmas de actualidad, que, bien mirado, la aceptación de la obra de Antonio Gamoneda, al final, resulta ser un misterio, e, independientemente de que naturalmente la celebre, diré que no se termina de entender bien cómo se ha podido producir. Hasta dónde yo puedo reconocerlo, este no es el mundo; esta no es propiamente la situación de mundo general que propiciaría el entendimiento, y ni siquiera la escucha, de una obra como la que este artífice de lo simbólico ha ido construyendo en largos y demorados ritmos marcados por un impromptu, abiertamente a contratiempo, intempestivamente diríamos. De alguna manera, este

\footnotetext{
${ }^{22}$ Extrañamiento, lejanía, distancia. Son valores «modernos» de lo literario que ha explorado recientemente C. Ginzburg (2000), Ojazos de madera. Siete ensayos sobre la distancia y que, añadimos nosotros, se sitúan frente a la axiología moderna de un estar-juntos, de una perfecta «comunión de los santos».

${ }^{23}$ T. Sánchez Santiago (2004), «El poeta fuera de tono», Espacio/Espaço escrito, 45-51.

${ }^{24}$ G. Debord (1976), La sociedad del espectáculo.

${ }^{25}$ B. Groys (2008), Bajo sospecha. Una fenomenología de los medios de comunicación.

${ }^{26}$ B. Groys (2005), Sobre lo nuevo. Ensayo de una economía de la cultura.

${ }^{27}$ H. Jenkins, Convergente Culture. La cultura de la convergencia de los medios de comunicación, op. cit.
} 
ya no es el momento para proceder a un desencantamiento, a un activo desengaño o des-ilusión de mundo, sino que, más bien, estamos situados ante el proceso imparable de su reencantamiento ${ }^{28}$.

Creo que algo de esto también siente el autor cuando elabora su famoso dictum en el 75; es decir, a las puertas mismas de lo que sería la definitiva consolidación de un modelo de capitalismo cultural que ha resultado al final como el modelo occidental más afectado por la transformación y el cambio de los parámetros tradicionales en que se movía el tradicional humanismo cultural ${ }^{29}$, al que podemos ciertamente dar por acabado ${ }^{30}:$ «Este no es mi lugar, pero he llegado» ${ }^{31}$.

Esto, en efecto, había dicho el poeta, dando acaso cuenta de esa doble extrañeza que el cuerpo bioliterario de nuestro autor experimenta verdaderamente ante el signo de un presente, donde, ciertamente, es evidente que no se le esperaba.

En adelante, me aplicaré a definir ese «lugar», que no es otro que el de un espacio de presente absoluto, con el cual, en realidad, la obra, si bien se mira, no dialoga.

Si hoy aquí nos acogemos bajo un principio de poderosa imprimación, cual es el de «divergencia», entonces, creo que ello nos autoriza suficientemente para encontrar el sentido a este que parece un destinador absoluto de la obra del poeta; en realidad puede pensarse que estamos ante una suerte de «empresa» o empeño y leitmotiv suyo, al modo de una seña identitaria, y si debemos armar este concepto fuerte, entonces tampoco cabe duda de que será remitiéndolo forzosamente a la escena máxima en que la cuestión puede ser situada.

La divergencia, una vez rechazada una lectura de la misma más simple, en cuanto posicionamiento de singularidad creativa en un campo de letras como el español -que en efecto, el autor ha conquistado--, debe leerse ahora con algo más de ambición conceptual; es decir: en cuanto ella compone una suerte de radical disenso frente a todo otro; frente a lo dado; frente a la actualidad misma; frente también, está claro, aquellos que la modelan con sus representaciones artísticas de legitimación, y que parece que ostentan la autoridad sobre el presente ${ }^{32}$.

Acudiendo ahora a una vieja expresión freudiana, la peculiaridad de esta obra que concelebramos aquí es que no resulta exaltadora de ningún momento cultural, ni puede ser en lo íntimo capitalizada como plusvalía del sistema, pues si algo expresa, ello es, justamente, el «malestar en la cultura» ${ }^{33} \mathrm{y}$ acaso esta vez, un paso más allá, la tragedia misma de la cultura entendida en su formulación más general $^{34}$. Una pulsión que va más allá del puro principio de placer y juego parece, pues, que la condiciona y determina. Todo, como se ve, muy lejos de la celebración hipostasiada de lo propia

\footnotetext{
${ }^{28}$ M. Maffesoli (2007), Le Réenchantement du monde. Une éthique pour notre temps.

${ }^{29} \mathrm{G}$. Vattimo ha referido este proceso vertiginoso de la sociedad española enfocada a la posmodernidad, caracterizando a la misma G. Vattimo (1990), La sociedad transparente.

${ }^{30}$ Uno de los textos más duros con el llamado humanismo escritófilo es el de P. Sloterdijk (2008), Normas para el parque humano.

31 «Descripción de la mentira», Gamoneda; Fernando R. de la Flor, Sílabas negras, op. cit., 98.

${ }^{32}$ La oposición de Gamoneda al ala triunfante de cierta poesía reconocida bajo el nombre de «poesía de la experiencia» es, como ya hemos hecho observar, total y se deja leer aquí y allá en sus manifestaciones.

${ }^{33}$ S. Freud (1970), El malestar en la cultura.

${ }^{34} \mathrm{Y}$ en términos que proceden por derecho propio del sociólogo G. Simmel, la «tragedia de la cultura»: G. Simmel (1988), «La tragedia de la cultura», en Sobre la aventura y otros ensayos.
} 
lectura de mundo en claves políticamente correctas a que los agentes simbólicos hoy se entregan, hablando, incluso, en ciertas ocasiones, de la «buena salud» de la poesía y de las letras españolas, pues, ciertamente, estas se han convertido en espacio de celebración de lo dado.

La divergencia, en el sentido «fuerte» en que aquí la reivindicamos para Antonio Gamoneda, no puede ser sino desacuerdo profundo con el tiempo-ahora, en lo que resulta ser la síntesis simbólica de mundo que sobre el mismo y su sentido final se practica. O por decirlo en otros términos: obvia divergencia, para este caso concreto, entre lo que es la cultura subjetiva, espiritual del propio Gamoneda con respecto a lo que en estos momentos representa la cultura objetiva, la cultura del Estado cultural; en definitiva de aquello de lo que se manifiesta hoy como cultura colectiva en tiempos del capitalismo tardío, lugar donde el espíritu colectivo se autopresenta a sí mismo.

Estoy tratando de insinuar que, en realidad, la obra toda de Antonio Gamoneda se muestra discorde, en grave desajuste con las figuraciones que rigen el imaginario de la posmodernidad. Punto por punto, tal obra se opone con gravedad inusitada a los paradigmas psicohistóricos que hoy construyen el sentido mismo de la realidad.

Apenas tendré tiempo ya sino para evidenciar esto: que la lectura de mundo que Gamoneda instrumenta en su texto está en abierta contraposición a la influencia que ejercen hoy los que pueden considerarse como valores representativos de una situación posmoderna. Ciertamente aquella que se ha alcanzado finalmente en el «interior acolchado» de la esfera del primer mundo, donde el capitalismo demoliberal ha alcanzado sus últimos objetivos y pretende haber clausurado la historia, habiéndola desposeído de ejemplaridad, aventando toda ética arcaica y suprimido el valor del drama en ella.

He dicho antes que la aceptación universal de la obra de Antonio Gamoneda podría recaer en la categoría de un misterio. Pero ahora deberé añadir que es en razón precisamente de su índice de divergencia, de -diríamos-, clinamen con respecto al paradigma que rige hoy en la construcción e interpretación de situaciones y elaboración de vivencias colectivas, lo que la hace en extremo valiosa (y necesitada también de una defensa crítica). Acaso sea esta la clave de su aceptación gratificadora, pues se ha hecho valiosa más por lo que niega que por lo que afirma, colaborando así en una cierta homeostática general del sistema.

La irrupción exitosa del grave mensaje gamonediano en el seno de un panorama de paradigmas consolidados como productos de una ultramodernidad, se debe precisamente al hecho de que ha logrado introducir en ese sistema lo que para el mismo es considerado como desvalorizado, ocluido, incluso fuertemente tabuizado, cuando no directamente reprimido ${ }^{35}$. He aquí que estancias clausuradas como «viejos armarios» del pasado ${ }^{36}$ se abren en una inspección indeseada, contradictoria con lo que es la concentración actual en los efectos del presente y del puro vivir en novedad, al albur de la lectura de circunstancias siempre cambiantes y excesivas.

\footnotetext{
${ }^{35}$ La obra de Gamoneda quizá se deje circunscribir en la categoría psicoanalítica de lo familiar vuelto extraño, e incluso, «siniestro» (unheimlich). Sigue siendo importante el estudio de S. Freud sobre ello: S. Freud (1990), Lo siniestro.

${ }^{36}$ Resultará obvia aquí la referencia al tratado de memorias que ha elaborado A. Gamoneda (2009) y que titula de modo desusado como Un armario lleno de sombra.
} 
Me referiré por un momento al pensamiento de la muerte y su corolario en el relato de la decrepitud, que en efecto constituyen el último tabú de la sociedad hipermoderna. Ambos, realmente desplazados de las cuestiones en juego de actualidad, y que en razón de esa ausencia, se han vuelto en obsesiva presencia en el registro incosciente de nuestro tiempo ${ }^{37}$. Enseguida, también, hay que afirmar que la cohorte misma de los sentimientos conexos a este campo de lo mortal se habría quedado hoy sin expresión, digamos sin «VOZ», ni representación discursiva propia, ello en una tradición propiamente española, que, con su punto de inflexión en los barrocos y su instante genealógico en Jorge Manrique, había hecho de ella el mensaje fuerte, aproximando el lenguaje a su esfera misma ${ }^{38}$; esto es: a la del duelo ${ }^{39}$, la del luto, la del dolor existencial, resuelto todo ello en un afrontamiento directo, sin ambages. Estamos ante el último autor que puede afirmar, y lo hace de nuevo fuera de la consideración del tiempo que vive lo social actual, que:

Esta es la tierra, donde el sufrimiento

Es la medida de los hombres. ${ }^{40}$

Habitante exclusivo de una tierra que ya no es la tierra, el país conocido, experimentado, con Gamoneda ha retornado el cuerpo indeseado de la organicidad oscura ${ }^{41}$, y lo ha hecho en el tiempo dominado por la especulación biotecnológica; tiempo por lo demás que ha instaurado en el corazón de las vivencias comunes la utopía de las prótesis, de las reparaciones y cirugías milagrosas. Cuerpo aquel otro, en cambio, construido por el poeta y por el que vuelven a ser segregados los fluidos tristes que gobiernan el sentimiento superior de una caducidad, que este mundo de avatares y de personalidades virtuales niega y, en todo caso, aspira a trascender con su continua representación de cuerpos en la forma de pieles estelares, auráticas, que no conocen la mácula de la putrefacción y que se encuentran plenamente desentendidos de la muerte ${ }^{42}$.

Desobedeciendo ciertos mandatos relativos a la necesaria ocupación en los procesos nuevos y en las experiencias factuales que el mundo de hoy prodiga, la textualidad de Gamoneda se dirige a la violenta desautorización de lo que conforma la situación y mundo de la vida al día de hoy, negando en bloque la obsesión informativa, la historia comunicacional que ha convertido a gran parte de la reciente poesía española en una fiel reproducción inventarial de las condiciones en que se desenvuelve la

\footnotetext{
${ }^{37} \mathrm{Si}$ no es por el tratamiento que todavía recibe por parte de analistas que operan en la periferia misma del main stream del pensamiento actual. Como V. Jankélevitch (2002), La muerte.

${ }^{38}$ En efecto, lenguaje y muerte, ello en la exploración que de la cuestión hace G. Agamben (2002), El lenguaje y la muerte. Un seminario sobre el lugar de la negatividad, y, en el fondo, también J. Derrida (2002), Dar (la) muerte.

${ }^{39}$ La conexión en este punto con la escritura de otro poeta próximo generacional y afectivamente a Antonio Gamoneda, que es Juan Gelman, es obvia. Véase para ello G. Fabry (2008), Las formas del vacío. La escritura del duelo en la poesía de Juan Gelman.

${ }^{40}$ Gamoneda; R. de la Flor, Sílabas negras, op. cit., 296.

${ }^{41}$ Organicidad relatada en el modo de su disolución, con lo que la obra se aproxima subrepticiamente al concepto de «inmundo», utilizado solo por una vanguardia altamente exigente e iconoclasta y de la que ha dado cuenta J. Claire (2007) en su De inmundo.

${ }^{42}$ Cuerpos que en la esfera del arte se presentan como intangibles dispuestos en una banda superficial. De esas y otras visiones de la corporalidad en la escena posmoderna da cuenta una miríada de trabajos de actualidad que aquí no citamos.
} 
moderna realidad. Estoy «perfectamente desinformado», ha resuelto de un plumazo el poeta, saldando así la cuestión que ocupa de manera dictatorial el presente.

La aceleración temporal ${ }^{43}$, el sentimiento de progreso y lo que también ha podido ser conocido en su versión más vitalista como «velocidad de escape» ${ }^{44}$, no parece hacer mella en esta escritura obstinada, que hace de la retención, de la demora, de la reticencia y la continuada remisión, estrategias conceptuales y retóricas que finalmente desautorizan lo que parece ser el compromiso ineludible que un productor simbólico, un intérprete de lo social, tendría con el hoy y sus propias mecánicas profundas. ¿Cómo no ver en todo ello una suerte de hipertrofia memorativa? La celebración de la memoria ya no parece ser sino una actividad simbólica residual en la época que se consagra toda ella al «presenteismo» ${ }^{45}$. En ese esquema actitudinal la lentitud se vuelve muda protesta contra la modernidad (siempre velociferina), y adopta la forma hiperbólica de un exceso de gesto que desafía los modos en que el presente transcurre.

Nuestro tiempo y nuestro mundo, el mundo en el que operan los textos de Gamoneda, es el mundo que ha podido ser definido como la sociedad del bienestar, y, un punto más allá, sociedad «del mimo» en su invernadero de consumo ${ }^{46}$, del acceso ya generalizado al lujo ${ }^{47}$, del hedonismo y la «felicidad paradójica» ${ }^{48}$, sin límites, algo que las jóvenes generaciones han aprendido rápidamente a cultivar, desechando las consideraciones del viejo humanismo funéreo ${ }^{49}$, al que en efecto, debemos dar por liquidado por lo menos de los usos de vida comunes que rigen en el hoy. Quizá sea en este punto donde la divergencia gamonediana es mayor, atada como está a conceptos de gran astringencia libidinal ${ }^{50}$. La vinculación a una idea de la historia humana en cuanto tragedia incomponible, y, sobre todo, su fidelidad expresa a la idea superior de una caducidad universal irredimible, en nada se comparece con una vivencia al presente de las masas, cuya cultura sigue la norma derridiana y, en general, psicoanalítica de desatenderse del fantasma de inutilidad y sin sentido de la propia vida humana $^{51}$, en aras de la potenciación del interés propio y de un loco amor sui, que al final ha acabado por imponerse, construyéndose los individuos como seres llamados mucho antes a la plenitud, que a

\footnotetext{
${ }^{43}$ Aceleración temporal, el concepto ha sido trabajado por R. Koselleck (2003), Aceleración, Prognosis y secularización. ${ }^{44}$ Véase en este sentido la obra del teórico de la posmodernidad, M. Derey (1998), Velocidad de escape.

${ }^{45}$ El neologismo evidencia la adoración teista por el presente, y ha sido puesta en circulación por M. Maffesoli (2009), Iconologías. Nuestras idolatrías postmodernas, 58.

${ }^{46}$ Curiosa definición que hace alusión a la esfera sobreprotegida en que se mueve la sociedad del «primer mundo". Véase ello en el libro de P. Sloterdijk, En el interior del mundo del capital, op. cit.

${ }^{47}$ Lujo democratizado que ha sido uno de los efectos más llamativos conseguidos por el capitalismo en su fase tardía, G. Lipovetsky, El lujo eterno: de la era de lo sagrado al tiempo de las marcas, op. cit.

${ }^{48}$ Para este concepto, véase G. Lipovetsky, La felicidad paradójica. Ensayo sobre la sociedad del hiperconsumo, op. cit.

${ }^{49}$ Algo que tuvo su punto de arranque en el tratado sesentayochista de R. Vaneigem (1967), Tratado de saber vivir para uso de jóvenes generaciones.

${ }^{50}$ Que esta astringencia se prolongue y penetre en una nueva situación psicohistórica caracterizada por la desinhibición y el deseo, eso es lo extraordinario. Véase, en todo caso, y para el abordaje de estas cuestiones, el último libro de S. Alba (2007), Capitalismo y nihilismo: dialéctica del hambre y la mirada, y, también, I. Castro Rey (2007), Votos de riqueza. La multitud del consumo y el silencio de la existencia.

51 Aquí el dictum de Derrida choca abiertamente con la síntesis e idea de mundo que pone en juego el discurso de Gamoneda.
} 
cualquier suerte de pérdida, de carencia, de nihilificación ${ }^{52}$. En efecto, Derrida dixit: es nuestro tiempo aquel en que para nada se estiman los discursos que se complacen en revelar la tristeza y la nulidad de mundo ${ }^{53}$.

El inventario de las disidencias y divergencias gamonedianas, con todo, no se acaba aquí, aunque yo si debo ir concluyendo este esbozo interpretativo, que trata de dar cuenta de una mecánica en todo momento situada «a contratiempo». En un universo ampliamente globalizado, anglosajonizado, las referencias que Gamoneda reintroduce en la circulación del sentido simbólico vuelven con fuerza a lo local, a los universos desgastados de la provincia y de lo rural, en cuyos vocabularios obsoletos el poeta es un maestro, el último de los maestros del genius loci, antes de que este explotara en un haz de dimensiones que incluyen ahora sobresalientemente la propiamente virtual (de la que el poeta, desde luego, de nuevo no quiere saber nada, y sobre la que afectará estar «perfectamente desinformado»). Sus blues castellanos irrumpen, pues, en un dominio con la fuerza de un oxímoron violento, poniendo en causa un espacio que resulta a la postre ser inviable en lo geopolítico y en lo psicohistórico, pero del que Antonio Gamoneda se hace garante, y, para decirlo en su propio vocabulario: «vigilante» ${ }^{54}$.

Son causas todas que nos obligaran en adelante a pensar, mas que propiamente, en las calidades que exhibe tal arte verbal, en la dialéctica misma que inaugura una existencia negadora entre nosotros, todo ello realizado en el seno del ágora moderna. Lo que está en juego es el destino último que lo trágico recibirá en el seno de la sociedad del bienestar ${ }^{55}$. Es lo que brevemente he pretendido expresar, haciendo causa eficiente de ese termino preciso, que quizá el poeta, con su modestia habitual, ha querido en último extremo dulcificar consciente de su temible potencial.

La divergencia que figura en el reclamo mismo de este volumen y convocatoria, es solo la cara amable de un disenso que cabe pensar como radical. La Obra con ello logra separarse del Mundo, en donde, sin embargo, debe seguir operando sus efectos. Este es el fondo ambiguo del asunto.

\section{Referencias bibliográficas}

AgAMBEN, Giorgio, El lenguaje y la muerte. Un seminario sobre el lugar de la negatividad, Valencia, Pre-Textos, 2002.

AlBA, Santiago, Capitalismo y nihilismo: dialéctica del hambre y la mirada, Barcelona, Akal, 2007.

BENJAMIN, Walter, «Experiencia y pobreza», Discursos interrumpidos I, Madrid, Taurus, 1989, 165175.

BORDIEU, Pierre, La distinción. Criterios y bases sociales del gusto, Madrid, Taurus, 1988.

\footnotetext{
52 Véase en este sentido la salida del viejo callejón a que conduce el humanismo victimista y los usos de pensamiento político correcto reflejados en el último volumen de la trilogía de P. Sloterdijk (2006), Esferas III.

${ }^{53}$ El principio de interés y cuidado de sí gobierna en absoluto la vida actual, realizando finalmente el ideal expreso en el capitalismo protestante. Véase en este punto, más allá de Max Weber, A. Hirschman (1999), Las pasiones y los intereses. ${ }^{54}$ El sentimiento de provincia en ello exhibido vincula su obra expresamente a la de un poeta como Claudio Rodríguez, además de alentar cierta escuela «local», «periférica», que se diría que vive de espaldas a la producción y campo literario establecido en las metrópolis peninsulares. He analizado pormenorizadamente estas cuestiones en mi libro en prensa Contra(post)modernos. Disidencia, carencia, provincia.

${ }^{55}$ Recordemos que este era el tema del famoso artículo de B. Strauss (1993), «Premoniciones de tragedia. El canto creciente del macho cabrío», Debats, 78-92.
} 
CASTRO REY, Ignacio, Votos de riqueza. La multitud del consumo y el silencio de la existencia, Madrid, Machado Libros, 2007.

ClaIRE, Jean, De inmundo, Madrid, Arena Libros, 2007.

DEBORD, Guy, La sociedad del espectáculo, Barcelona, Castellote Editor, 1976.

Deleuze, Gilles y Guattari, Félix, Kafka. Por una literatura menor, México, Ediciones Era, 1975.

DEREY, Mark, Velocidad de escape, Madrid, Siruela, 1998.

DERRIDA, Jacques, Dar (la) muerte, Barcelona, Paidós, 2002.

FABRY, Genevieve, Las formas del vacío. La escritura del duelo en la poesía de Juan Gelman, Ámsterdam, Rodopi, 2008.

FREUD, Sigmund, El malestar en la cultura, Madrid, Alianza, 1970.

-, Lo siniestro, Buenos Aires, JCE Ediciones, 1990.

FUMAROLI, Marc, El «estado cultural»: de la oligarquía demagógica a la conversión de la cultura en mercancía publicitaria, Barcelona, Acantilado, 2007.

GAMONEDA, Antonio, «Palabras pronunciadas por Antonio Gamoneda al recoger el Premio Cervantes de Literatura en Alcalá de Henares», República de las Letras, núm. 104 (2007), 147-155.

-, Un armario lleno de sombra, Madrid, Galaxia Gutenberg-Círculo de Lectores, 2009.

GINZBurg, Carlo, Ojazos de madera. Siete ensayos sobre la distancia, Barcelona, Península, 2000.

GROYs, Boris, Bajo sospecha. Una fenomenología de los medios de comunicación, Valencia, PreTextos, 2008.

-, Sobre lo nuevo. Ensayo de una economía de la cultura, Valencia, Pre-Textos, 2005.

GONZÁlEZ, Ángel, El Resto. Una historia invisible del arte contemporáneo, Bilbao, Museo de BBAA., MNCARS, 2000.

Gumbrecht, Hans, Producción de presencia. Lo que el significado no puede transmitir, México, Universidad iberoamericana, 2005.

HeIDEGGER, Martín, La pobreza, Madrid, Amorrourtu, 2006.

HIRSCHMAN, Albert, Las pasiones y los intereses, Barcelona, Península, 1999.

JANKÉLEVITCH, Vladimir, La muerte, Valencia, Pre-Textos, 2002.

JENKINS, Henry, Convergente Culture. La cultura de la convergencia de los medios de comunicación, Barcelona, Paidós, 2009.

Koselleck, Reinhart, Aceleración, Prognosis y secularización, Valencia, Pre-Textos, 2003.

LANZ, Juan José, «La memoria y su silencio: Descripción de la mentira (1977) de Antonio Gamoneda

y la memoria callada del franquismo y de la Transición», Anales, núm. 21 (2009), 101-116.

Lipovetsky, Gilles, La Felicidad Paradójica. Ensayo sobre la Sociedad del Hiperconsumo, Barcelona, Anagrama, 2007.

-, El lujo eterno: de la era de lo sagrado al tiempo de las marcas, Barcelona, Anagrama, 2004.

MAFFESOLI, Michel, Le Réenchantement du monde. Une éthique pour notre temps, París, La Table Ronde, 2007.

-, Iconologías. Nuestras idolatrías postmodernas, Barcelona, Península, 2009. 
MARTínez GARCíA, Francisco, Gamoneda, una poética temporalizada en el espacio leonés, León, Universidad de León, 1991.

MAte, Manuel-Reyes, Medianoche en la historia. Comentarios a las tesis de Walter benjamín «sobre el concepto de historia», Madrid, Trotta, 2006.

NAVARro, Vicenç, El subdesarrollo social en España, Barcelona, Anagrama, 2006.

OCAÑA, Enrique, El duelo por la historia, Valencia, Pre-Textos, 2000.

Rodríguez DE LA Flor, A. Gamoneda, Sílabas negras, Salamanca, Servicio de Publicaciones Universidad de Salamanca, 2006.

-, La era melancólica. Figuras del imaginario barroco, Madrid, Juan de Olañeta, 2007.

-, «Glocal. Claudio Rodríguez y al poética de la provincia», Aventura. Revista anual del Seminario Claudio Rodríguez, núm. 2 (2008), 48-73.

-, Contra(post)modernos. Disidencia, carencia, provincia, Mérida, Periférica (en prensa).

SÁNCHEZ SANTIAGO, Tomás, «El poeta fuera de tono», Espacio/Espaço escrito, núms. 23-24 (2004), 45 51.

SIMMEL, Georg, «La tragedia de la cultura», Sobre la aventura y otros ensayos, Barcelona, Península, 1988.

SLOTERDIJK, Peter, Extrañamiento de mundo, Valencia Pre-Textos, 2001.

-, En el interior del mundo del capital, Madrid, Siruela, 2008.

-, Normas para el parque humano, Madrid, Siruela, 2008.

-, Esferas III, Madrid, Siruela, 2006.

STRAUSS, Botho, «Premoniciones de tragedia. El canto creciente del macho cabrío», Debats, núm. 45 (1993), 78-92.

Todorov, Tzvetan, Los abusos de la memoria, Barcelona, Paidós, 2000

TrAPIELlo, Andrés, Otra vez el ayer. Los intelectuales ante al Guerra Civil, Madrid, Casa del Libro, 1996.

VANEIGEM, Raoul, Tratado de saber vivir para uso de jóvenes generaciones, Barcelona, Anagrama, 1967.

VAtтimo, Gianni, La sociedad transparente, Barcelona, Paidós, 1990. 